\title{
13. Chemical Reaction at High Temperature and High Pressure. II
}

\author{
Reaction of Boron and Arsenic at High \\ Temperature and High Pressure*)
}

\author{
By Jiro Osugi, Kiyoshi Shimizu, and Yoshiyuki Tanaka \\ Department of Chemistry, Kyoto University \\ (Comm. by Shinkichi HoRIBA, M.J.A., Jan. 12, 1966)
}

Introduction. In the previous paper, ${ }^{11}$ the reaction of amorphous boron and red phosphorus at high temperature and high pressure was reported. Now, the reaction of direct union of boron and arsenic, which is one of the elements in the same group V of phosphorus, has been investigated under high temperatures of $1150-1400^{\circ} \mathrm{C}$ and high pressures of $2-33 \mathrm{~kb}$.

Up to date, J. A. Perri, S. LaPlaca, and B. Post in $1958{ }^{2)}$ and F. V. Williams and R. A. Ruehrwein in $1960,{ }^{3)}$ prepared cubic BAs and rhombohedral $\mathrm{B}_{13} \mathrm{As}_{2}$ by reacting boron halides with arsenic and arsine in sealed silica tubes and reported their X-ray diffraction data.

The effects of pressure, temperature, reaction time and the atomic ratio of mixing boron and arsenic on the reaction yields of boron arsenides, and the reaction mechanism have been investigated.

Experimentals. Materials. Extra pure grade amorphous boron and gray arsenic were mixed in the atomic ratio of $\mathrm{B}: \mathrm{As}=1: 1$ and $13: 2$ in a mortar.

High pressure technique. In the pressure range of $2-16 \mathrm{~kb}$ the high pressure equipment was similar to that used previously, ${ }^{11}$ except that the powder sample was placed in a carbon tube directly without a platinum capsule since arsenic reacts easily with platinum in the experimental condition to form $\mathrm{PtAs}_{2}$.

In the pressure range of $20-40 \mathrm{~kb}$ the compact cubic anvil apparatus was used. ${ }^{4)}$ The general principle and the details of the construction of the apparatus are shown in Fig. 1. By this apparatus the external ram force, which is applied to only one vertical axis, is converted to the six equivalent components of force which act on the cubic pyrophyllite along the three rectangular axes and the flat faces of the six anvils are then forced to advance equally toward the center of cube and always to form the cube with increasing

*) Contributed to the International Conference on High Pressure, Le Creusot, France, August 4, 1965. 

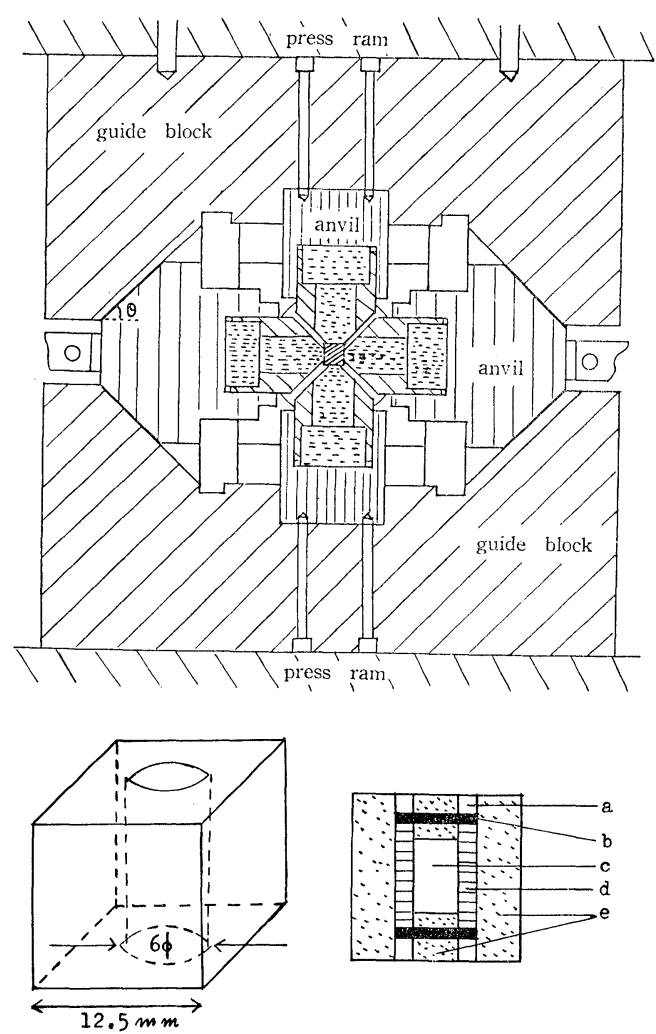

A

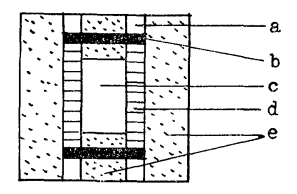

B
Fig. 1. The vertical cross section of the compact cubic anvil apparatus.

pressure. The sample placed in a glassy carbon was inserted into the pyrophyllite cube. The cross section of pyrophyllite cube is shown in Fig. 2.

Analysis. After the reaction the sample was powdered in an agate mortar and analysed by chemical method and X-ray diffraction.

Chemical analysis was essentially that used in previous work. ${ }^{1)}$ Chemically inert $\mathrm{B}_{13} \mathrm{As}_{2}$ was filtered, dried and weighed. BAs, which could not be determined chemically, was determined indirectly by $\mathrm{X}$-ray, diffraction analysis. The calibration curves of $\mathrm{B}_{13} \mathrm{As}_{2}$ and $\mathrm{As}$ were obtained using $\mathrm{NaCl}(d=1.99 \AA)$ as a standard material.

Results and considerations. Determination of products. By $\mathrm{X}$-ray diffraction data for two reaction products, one of the reaction products has a cubic zinc-blende structure and the lattice constant is $4.78 \AA$, which is in good agreement with experimental data of J. A. Perri' ${ }^{2)}$ and F. V. Williams. ${ }^{3)}$ Another reaction product, which was isolated and confirmed chemically, has a rhombohedral structure and the lattice constant is $5.319 \AA, \alpha=70^{\circ} 32$ ', which is in good agreement with experimental data of $\mathrm{S}$. LaPlaca et $a l_{0^{2,5), 6)}}$ 
Effects of pressure, temperature and the atomic ratio of boron and arsenic on the reaction yields of $B A s$ and $B_{13} A s_{2}$.

I. In the case of $B: A s=1: 1$ sample. The variations of mole fraction of $\mathrm{BAs}$ and $\mathrm{B}_{13} \mathrm{As}_{2}$ formed in 60 minutes with pressure (2$16 \mathrm{~kb}$ ) at 1200 and $1300^{\circ} \mathrm{C}$ are shown in Fig. 3. In this case the amount of boron is too small to form $\mathrm{BAs}$ and $\mathrm{B}_{13} \mathrm{As}_{2}$ at the same time. Namely in the most experimental conditions boron was consumed completely to form chiefly $\mathrm{BAs}$ and $\mathrm{B}_{13} \mathrm{As}_{2}$.

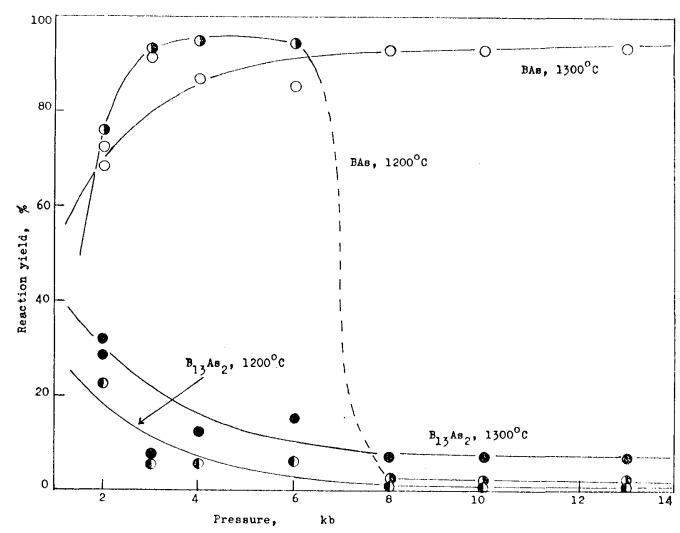

Fig. 3. Variation of reaction yields of BAs and $\mathrm{B}_{13} \mathrm{As}_{2}$ formed in 60 minutes with pressure at 1200 and $1300^{\circ} \mathrm{C}$ in the case of $\mathrm{B}: \mathrm{As}=1: 1$ sample.

The reaction yield of $\mathrm{BAs}$ increases with pressure up to $6 \mathrm{~kb}$ at both 1200 and $1300^{\circ} \mathrm{C}$. It may arise from the effect of pressure according to Le Chatelier's principle, since the molecular volume of BAs is smaller than the sum of atomic volumes of $B$ and As by $2.9 \mathrm{cc} / \mathrm{mole}$, which is calculated crystallographically.

In the pressure range from $2 \mathrm{~kb}$ to $6 \mathrm{~kb}$ the reaction yield of $\mathrm{BAs}$ at $1200^{\circ} \mathrm{C}$ surpasses that at $1300^{\circ} \mathrm{C}$. It may be due to that $\mathrm{BAs}$ once formed changes into $\mathrm{B}_{13} \mathrm{As}_{2}$ at $1300^{\circ} \mathrm{C}$ faster than at $1200^{\circ} \mathrm{C}$, as follows;

$$
2 \mathrm{BAs}+11 \mathrm{~B} \longrightarrow \mathrm{B}_{13} \mathrm{As}_{2} \text {. }
$$

The reaction yield of $\mathrm{B}_{13} \mathrm{As}_{2}$ decreases gradually with pressure at both temperatures. It would be due to that the reaction of BAs and $B$ is retarded with increasing pressure, since the amount of boron is too small in the $\mathrm{B}: \mathrm{As}=1: 1$ sample.

At $1200^{\circ} \mathrm{C}$, both $\mathrm{BAs}$ and $\mathrm{B}_{13} \mathrm{As}_{2}$ were not formed in the higher pressure range above $8 \mathrm{~kb}$. In these experimental conditions unknown reaction would take place between boron and arsenic, because the amount of the unreacted arsenic after reaction is rather small. 
II. In the case of $B: A s=13: 2$ sample. The variations of mole fraction of $\mathrm{BAs}$ and $\mathrm{B}_{13} \mathrm{As}_{2}$ formed in 60 minutes with pressure $(2-15 \mathrm{~kb})$ at 1250 and $1300^{\circ} \mathrm{C}$ are shown in Fig. 4. In these experimental conditions arsenic was consumed completely to form BAs and $\mathrm{B}_{13} \mathrm{As}_{2}$ in contrast to $\mathrm{B}: \mathrm{As}=1: 1$ sample.

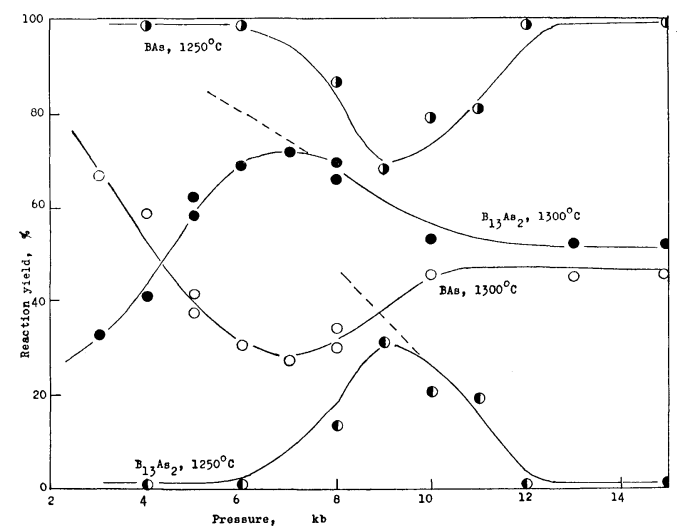

Fig. 4. Variation of reaction yields of BAs and $\mathrm{B}_{13} \mathrm{As}_{2}$ formed in 60 minutes with pressure at 1250 and $1300^{\circ} \mathrm{C}$ in the case of $\mathrm{B}: \mathrm{As}=13: 2$ sample.

Though only $\mathrm{BAs}$ is formed at $1250^{\circ} \mathrm{C}$ in the pressure range below $6 \mathrm{~kb}$ and above $12 \mathrm{~kb}$, the reaction yield of $\mathrm{B}_{13} \mathrm{As}_{2}$ increases with pressure from $7 \mathrm{~kb}$ to $9 \mathrm{~kb}$, which would arise from the reaction $2 \mathrm{BAs}+11 \mathrm{~B} \longrightarrow \mathrm{B}_{13} \mathrm{As}_{2}$, since the amount of boron is rich enough in this sample and the change of molecular volume of the reaction, $\Delta \mathrm{V}$, is calculated to be about $-25.7 \mathrm{cc} / \mathrm{mole}$ crystallographically.

The reason of the decrease of the reaction yield of $\mathrm{B}_{13} \mathrm{As}_{2}$ above $9 \mathrm{~kb}$ is uncertain. As mentioned above, the volume change of reaction in this system is negative, so the pressure coefficient of the reaction yield at equilibrium should be positive. But this does not consist with that the reaction yield of $\mathrm{B}_{13} \mathrm{As}_{2}$ decreases with pressure above $8 \mathrm{~kb}$. It would probably arise from the change of the reaction mechanism due to the transition of phase of the reactants and/or products.

At $1300^{\circ} \mathrm{C}$ the reaction yield of $\mathrm{B}_{13} \mathrm{As}_{2}$ increases with pressure since $\mathrm{BAs}$ once formed changes into $\mathrm{B}_{13} \mathrm{As}_{2}$ with increasing pressure. Above $10 \mathrm{~kb}$, the reaction yield of $\mathrm{B}_{13} \mathrm{As}_{2}$ is about $55 \%$ in 60 minutes. The fact that the reaction yield is independent of pressure would be due to the transition of phase of reactants and/or products.

At $1350^{\circ} \mathrm{C} \mathrm{B}_{13} \mathrm{As}_{2}$ is the main product under pressures of $30-33 \mathrm{~kb}$. Variation of the reaction yields of $B A s$ and $B_{13} A s_{2}$ with reaction 
time in the case of $B: A s=13: 2$ sample. Under the condition of $1250^{\circ} \mathrm{C}$ and $4 \mathrm{~kb}$, the reaction yield of BAs attains to $100 \%$ within 15 minutes, but $\mathrm{B}_{13} \mathrm{As}_{2}$ is not formed. At $1250^{\circ} \mathrm{C}, 8 \mathrm{~kb}$ (Fig. 5), the reaction yield of $\mathrm{BAs}$ attains to $100 \%$ within 15 minutes, and $\mathrm{B}_{13} \mathrm{As}_{2}$ increases linearly with lapse of reaction time from 30 to 90 minutes and the reaction does not attain to the equilibrium within 90 minutes. Under these conditions As in the sample is changed completely to the products of $\mathrm{BAs}$ and/or $\mathrm{B}_{13} \mathrm{As}_{2}$. Then, as shown by the dotted line in the figure, the reaction yield of BAs would decrease with lapse of reaction time after 15 minutes corresponding to the increase of the reaction yield of $\mathrm{B}_{13} \mathrm{As}_{2}$. In the condition of $1250^{\circ} \mathrm{C}$ and 11 $\mathrm{kb}$ (Fig. 6), the reaction yield of $\mathrm{B}_{13} \mathrm{As}_{2}$ increases with reaction time and reaches at the equilibrium in 60 minutes.

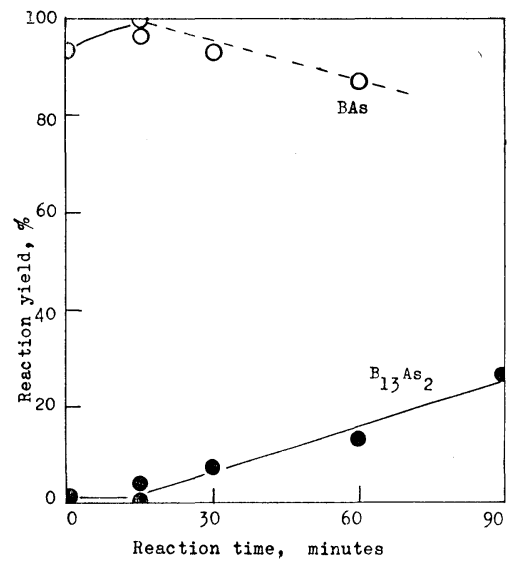

Fig. 5. Variation of the reaction yields of $\mathrm{BAs}$ and $\mathrm{B}_{13} \mathrm{As}_{2}$ with reaction time at $1250^{\circ} \mathrm{C}, 8 \mathrm{~kb}$.

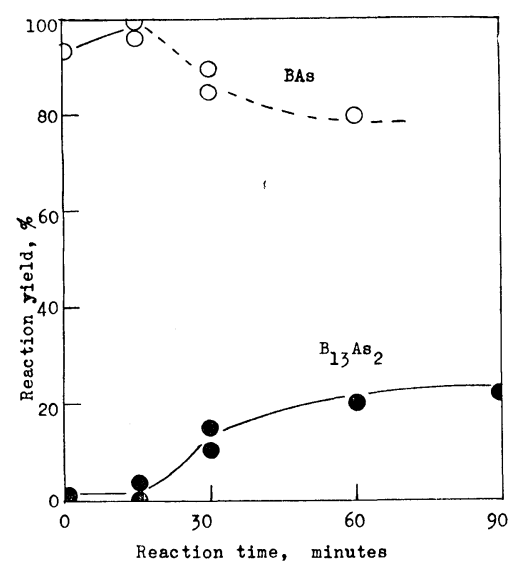

Fig. 6. Variation of the reaction yields of $\mathrm{BAs}$ and $\mathrm{B}_{13} \mathrm{As}_{2}$ with reaction time at $1250^{\circ} \mathrm{C}, 11 \mathrm{~kb}$.

At $1300^{\circ} \mathrm{C}$ and $9 \mathrm{~kb}, \mathrm{~B}_{13} \mathrm{As}_{2}$ is already formed about $10 \%$ at zero reaction time, and then the reaction yield of $\mathrm{B}_{13} \mathrm{As}_{2}$ increases gradually for 60 minutes with reaction time.

At $1325^{\circ} \mathrm{C}, 1350^{\circ} \mathrm{C}$, and $9 \mathrm{~kb}$, the rate of reaction is so high that the reaction yields of $\mathrm{B}_{13} \mathrm{As}_{2}$ are about 60 and $70 \%$ at zero reaction time respectively and are almost constant for 60 minutes of reaction time.*)

Effect of temperature on the reaction yield of $B A s$ and $B_{13} A s_{2}$ in the case of $B: A s=13: 2$ sample. The reaction yield of BAs increases markedly with temperature above $1150^{\circ} \mathrm{C}$ and attains to

*) At higher temperature, another reaction, $13 \mathrm{~B}+2 \mathrm{As} \rightarrow \mathrm{B}_{13} \mathrm{As}_{2}$, may be considered too. ${ }^{6)}$ 
$100 \%$ at $1200^{\circ} \mathrm{C}$. On the other hand, $\mathrm{B}_{13} \mathrm{As}_{2}$ is not formed up to $1200^{\circ} \mathrm{C}$ and then increases rapidly with temperature up to $1300^{\circ} \mathrm{C}$ which are shown in Fig. 7. Above $1300^{\circ} \mathrm{C}$, the increase of the reaction yield of $\mathrm{B}_{13} \mathrm{As}_{2}$ is rather slow. As shown with the dotted line in the figure, the yield of BAs decreases corresponding to the increase of the yield of $\mathrm{B}_{13} \mathrm{As}_{2}$ because of the reaction of $\mathrm{BAs}$ with $\mathrm{B}$ to $\mathrm{B}_{13} \mathrm{As}_{2}$.

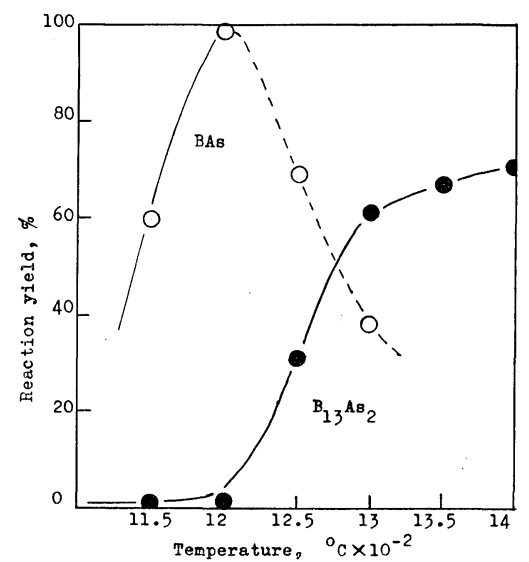

Fig. 7. Variation of the reaction yields of BAs and $\mathrm{B}_{13} \mathrm{As}_{2}$ with temperature in 60 minutes at $9 \mathrm{~kb}$.

Reaction of $B_{13} A s_{2} \longrightarrow 2 B A s+11 B$. The reaction of $\mathrm{B}_{13} \mathrm{As}_{2} \longrightarrow$ $2 \mathrm{BAs}+11 \mathrm{~B}$ was examined under the pressure of $30 \mathrm{~kb}$ at $1350^{\circ} \mathrm{C}$ in 150 minutes using the isolated $\mathrm{B}_{13} \mathrm{As}_{2}$ as the reactant. At $30 \mathrm{~kb}$, only the strongest diffraction line (111) of BAs is observed and the majority of the reactant, $\mathrm{B}_{13} \mathrm{As}_{2}$ does not change in agreement with the positive volume change of the decomposition reaction.

In conclusion, $\mathrm{BAs}$ and $\mathrm{B}_{13} \mathrm{As}_{2}$ is mainly formed by the following processes from boron and arsenic under high temperatures and high pressures:

$$
\mathrm{B}+\mathrm{As} \longrightarrow \mathrm{BAs} \stackrel{\mathrm{B}}{\longrightarrow} \mathrm{B}_{13} \mathrm{As}_{2} \text {. }
$$

The authors have great pleasure in expressing their sincere thanks to the Department of Education for the Grant in Aid.

\section{References}

1) J. Osugi, K. Shimizu, and Y. Tanaka: Proc. Japan Acad., 40, 105 (1964).

2) J. A. Perri, S. LaPlaca, and B. Post: Acta Cryst., 11, 310 (1958).

3) F. V. Williams and R. A. Ruehrwein: J. Am. Chem. Soc., 82, 1330 (1960).

4) J. Osugi, K. Shimizu, K. Inoue, and K. Yasunami: Rev. Phys. Chem. Japan, 34, 1 (1964).

5) A. H. Silver and P. J. Bray: J. Chem. Phys., 31, 247 (1959).

6) V. I, Matkovich: J, Am. Chem. Soc., 83, 1804 (1961). 